\title{
The oxidative metabolism of circulating phagocytes in ankylosing spondylitis: determination by whole blood chemiluminescence
}

\author{
Kuo-Jang Ho, Po-Quang Chen, Chiung-Yu Chang, Fung-Jou Lu
}

\begin{abstract}
Objective-Superoxide anion radicals within the human body are regarded as a major cause of inflammation. However, their role in the pathogenesis of ankylosing spondylitis (AS) has not been well identified. This study aimed at investigating the relation between AS and the oxidative metabolism of phagocytes in whole blood.

Methods-24 patients with classic AS were examined to determine their clinical status; complete blood count, erythrocyte sedimentation rate (ESR), and $\mathrm{C}$ reactive protein (CRP) were determined, and levels of the superoxide anion radicals in the patients with AS and 21 healthy subjects were assessed by the ultraweak chemiluminescence method. Subsequently, the relation between this disease and phagocytes was examined by using $\boldsymbol{N}$-formylmethionyl-leucyl-phenylalanine (fMLP) and phorbol-12-myristate-13-acetate (PMA) stimulants.
\end{abstract}

Results-In clinical assessments, patients with AS had abnormally raised serum CRP ( $>10 \mathrm{mg} / 1)$ and $\operatorname{ESR}(>15 \mathrm{~mm} / 1 \mathrm{st} \mathrm{h})$ levels. In contrast with healthy subjects, patients with AS had significantly increased rates of superoxide anion radical production in their whole blood either in the resting state or with either fMLP or PMA stimulation. In addition, chemiluminescence maximum light intensity was significantly higher in patients with AS than in healthy subjects after fMLP or PMA stimulation.

Conclusions-Our results suggest that the phagocytes of patients with AS are partly activated in the resting state, and are sensitive to $\mathrm{AMLP}$ or PMA stimulation. The priming of phagocytes in the bloodstream is likely to be a causative factor in the onset of AS.

(Ann Rheum Dis 2000;59:338-341)

Ankylosing spondylitis (AS) is an inflammatory disorder of unknown cause that mainly affects the axial skeleton as well as the peripheral joints and extra-articular structures. The enthesis, the site of tendinous or ligamentous attachment to bone, is another common site of disease in AS, especially around the area of the spine and pelvis. The most common symptoms are low back pain, morning stiffness, decreased spinal mobility, and even kyphotic deformity, all of which hinder daily activities greatly. AS usually begins in the second or third decade and the prevalence in men is about three times that in women. Although the pathogenesis of AS is yet unknown, a combination of genetic and environmental factors probably plays a part. Several studies suggest that the HLA-B27 gene is present in more than $90 \%$ of patients with AS, particularly in North American white people, ${ }^{1}$ and raised serum titres of antibodies to certain enteric bacteria, particularly K pneumoniae, are common in patients with AS. Based on consistent findings of raised antibodies to klebsiella, ${ }^{2}$ and the presence of molecular mimicry between HLA-B27 and K pneumoniae nitrogenase, ${ }^{3}$ AS can be considered as an arthritic disease following $K$ pneumoniae infection in HLA-B27 positive patients. ${ }^{4}$ However, the exact role of molecular mimicry in the pathogenesis of AS remains to be determined.

Free radicals exist abundantly in the physiological environment and are unstable. They can damage biological molecules and cause malfunctions and diseases in the human body. Inappropriate release of oxygen free radicals and proteolytic enzymes from activated polymorphonuclear leucocytes (PMNs), both in the bloodstream and synovial fluid of patients with rheumatoid arthritis (RA), is responsible for joint and other tissue damage. ${ }^{5}$ AS, like RA, is one of the inflammatory arthritic diseases, and therefore we wish to address the question of whether free radicals might be directly detected in the whole blood of patients with AS.

In our study we used the lucigenin (bis- $N$ methylacridinium nitrate) enhanced chemiluminescence method $^{6}$ to assess the content of superoxide anion radicals in the whole blood of both patients with AS and healthy subjects in the presence or absence of $N$-formylmethionyl-leucyl-phenylalanine (fMLP) and phorbol-12-myristate-13-acetate (PMA) The purpose of this study is to investigate the relation between AS and the oxidative metabolism of phagocytes.

Table 1 Clinical characteristics of patients with ankylosing spondylitis

\begin{tabular}{llll}
\hline Number & $\begin{array}{l}\text { Mean age, } \\
\text { years (range) }\end{array}$ & $\begin{array}{l}\text { Mean ESR* (SE) } \\
(\mathrm{mm} / 1 \text { st } h)\end{array}$ & $\begin{array}{l}\text { Mean CRP* } \\
(S E)(m g / l)\end{array}$ \\
\hline 24 & $35.6(19-54)$ & $\begin{array}{l}31.2(6.6) \\
<15(\mathrm{n}=9)\end{array}$ & $\begin{array}{l}22.0(6.5) \\
<10(\mathrm{n}=14) \\
\end{array}$ \\
& $\geqslant 15(\mathrm{n}=15)$ & $\geqslant 10(\mathrm{n}=10)$
\end{tabular}

${ }^{\star} \mathrm{ESR}=$ erythrocyte sedimentation rate; $\mathrm{CRP}=\mathrm{C}$ reactive protein; $\mathrm{n}=$ number of patients.

The normal values for ESR and CRP are $<15 \mathrm{~mm} / 1 \mathrm{st} \mathrm{h}$ and $<8 \mathrm{mg} / \mathrm{l}$, respectively. 


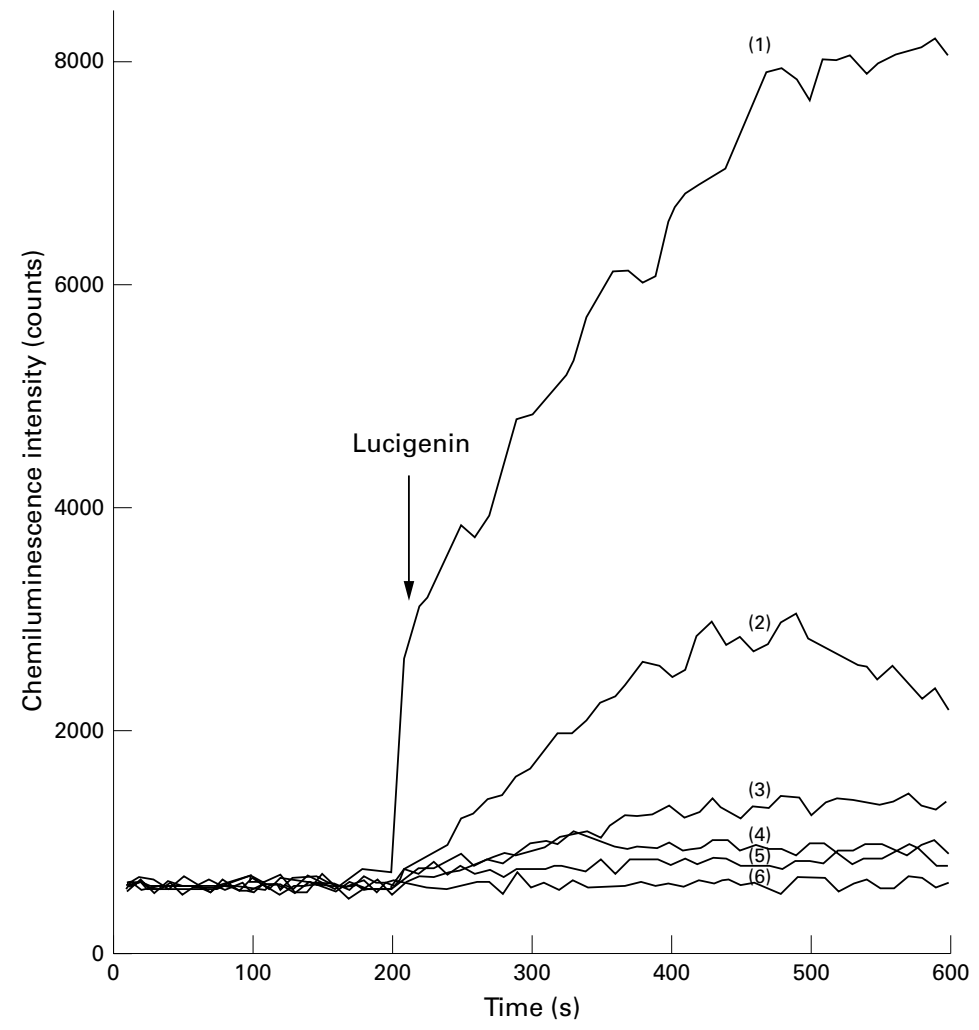

Figure 1 Comparisons of superoxide anion radicals in whole blood between one patient with $A S$ and one healthy subject using the lucigenin enhanced ultraweak chemiluminescence method. $0.2 \mathrm{ml}$ of heparinised blood was mixed with $0.1 \mathrm{ml}$ of phosphate buffered saline ( $\mathrm{pH}$ 7.4), N-formyl-methionyl-leucyl-phenylalanine (fMLP; $\left.1 \times 10^{-5} \mathrm{~mol} / \mathrm{l}\right)$ or phorbol-12-myristate-13-acetate (PMA;10 $\mathrm{\mu g} / \mathrm{ml})$ at $37^{\circ} \mathrm{C}$. Then, $1 \mathrm{ml}$ lucigenin $(0.01$ mmol/l) was added 200 seconds later. The levels of superoxide anion radicals in one patient with $A S$ and one healthy subject were assessed by the ultraweak chemiluminescence method. (1) $A S+P M A$; (2) $A S+f M L P$; (3) healthy subject $+P M A$; (4) healthy subject + fMLP; (5) AS only; (6) healthy subject only.

\section{Patients and methods}

PATIENTS

Samples from 24 male patients with AS (aged 19-54 years, with a mean age of 35.6), who fulfilled the New York criteria ${ }^{7}$ for definite diagnosis of AS, were collected from the outpatient clinic of the Department of Orthopaedic Surgery, National Taiwan University Hospital. All these patients were HLA-B27 positive and had not taken non-steroidal anti-inflammatory drugs in the past two weeks. They were compared with 21 healthy subjects (aged 22-47 years, with a mean age of 30.2) selected from the students and teachers of the Medical College, National Taiwan University. Peripheral venous blood from the subjects was mixed with sodium heparin in tubes covered with aluminium foil and was stored in ice until used for the assay.

LABORATORY INVESTIGATIONS

Complete blood count, C reactive protein (CRP), and erythrocyte sedimentation rate (ESR) were measured on the same day. The CRP concentrations were determined by the single radial immunodiffusion method of Mancini et al, ${ }^{8}$ (normal $<10 \mathrm{mg} / \mathrm{l}$ ) and the ESR levels of patients with AS were measured by the Westergren method (normal $<15 \mathrm{~mm} / 1 \mathrm{st} \mathrm{h}$ ).

DETERMINATION OF SUPEROXIDE ANION RADICALS IN WHOLE BLOOD

The content of superoxide anion radicals in whole blood was measured at $37^{\circ} \mathrm{C}$ by the ultraweak chemiluminescence method as used by $\mathrm{Lu}$ et $a .^{6}$ In brief, $0.2 \mathrm{ml}$ of heparinised blood was mixed with $0.1 \mathrm{ml}$ of phosphate buffered saline (pH 7.4), fMLP $\left(1 \times 10^{-5} \mathrm{~mol} /\right.$ 1), or PMA $(10 \mu \mathrm{g} / \mathrm{ml})$. The chemiluminescence intensity (CLI) was measured for 200 seconds at 10-second intervals using the Chemiluminescence Analysing System (Tohoku Electronic Ind. Co, Sendai, Japan). One millilitre of lucigenin $(0.01 \mathrm{mmol} / \mathrm{l})$ was added to this mixture when measurement was complete, and then the CLI was recorded continuously every 10 seconds for a total of 400 seconds. The total CLI counts were calculated by deducting the background value (the area of CLI that was equal to three times that of the first 200 seconds) from the total area of CLI (the total area of CLI within 600 seconds). The rate of superoxide anion radical generation was expressed as counts $/ 10 \mathrm{~s} / 10^{5}$ phagocytes. To calculate the value of the chemilumuinescence maximal light intensity (CMLI), the average CLI value of the first 200 seconds was subtracted from the highest CLI of the last 400 seconds and the result divided by the phagocyte count.

STATISTICAL ANALYSIS

The means of superoxide production rates and CMLI in patients with AS and healthy subjects were compared with Mann-Whitney's nonparametric U test. All data were expressed as means (standard error). Significance was set at $\mathrm{p}<0.05$.

\section{Results}

In clinical assessments, patients with AS had a raised $\operatorname{ESR}(>15 \mathrm{~mm} / 1 \mathrm{st} \mathrm{h})$ and a high

Table 2 Production of superoxide anion radicals measured by chemiluminescence

\begin{tabular}{|c|c|c|c|c|}
\hline & \multicolumn{2}{|c|}{ Production rate (counts/10 s/10 phagocytes) } & \multicolumn{2}{|c|}{$C M L I^{\star}$ (counts $/ 10 \mathrm{~s} / 10^{5}$ phagocytes) } \\
\hline & Healthy subjects & Patients with AS & Healthy subjects & Patients with $A S$ \\
\hline Resting & $\begin{array}{l}6.2(1.5)(0-26.1) \\
(\mathrm{n}=21, \text { age } 22-47)\end{array}$ & $\begin{array}{l}60.9(18.6)(0-354.7) \dagger \\
(\mathrm{n}=24, \text { age } 19-54)\end{array}$ & ND & ND \\
\hline $\mathrm{fMLP}^{\star}$ & $\begin{array}{l}34.9(5.9)(4.9-62.8) \\
(\mathrm{n}=9, \text { age } 23-42)\end{array}$ & $\begin{array}{l}178.8(36.9)(9.2-498.2) \dagger \\
(\mathrm{n}=18, \text { age } 19-54)\end{array}$ & $59.8(11.3)(17.5-131.9)$ & $237.2(45.0(17.2-584.2) \dagger$ \\
\hline $\mathrm{PMA}^{\star}$ & $\begin{array}{l}105.2(19.1) \\
(33.6-194.4) \\
(\mathrm{n}=9, \text { age } 23-42)\end{array}$ & $\begin{array}{l}583.0(112.8) \\
(87.2-2006.3) \dagger \\
(\mathrm{n}=20, \text { age } 19-54)\end{array}$ & $\begin{array}{l}150.2(25.6) \\
(56.5-282.5)\end{array}$ & $\begin{array}{l}766.5(127.1 \\
(139.2-2166.5) \dagger\end{array}$ \\
\hline
\end{tabular}

${ }^{\star} \mathrm{CMLI}=$ chemiluminescence maximal light intensity; fMLP $=\mathrm{N}$-formyl-methionyl-leucyl-phenylalanine; PMA $=$ phorbol-12myristate-13-acetate; $\mathrm{n}=$ number of patients; $\mathrm{ND}=$ not done.

All results are expressed as mean (standard error) (range).

$t \mathrm{p}<0.01$ compared with healthy subjects by Mann-Whitney $U$ test. 
concentration of CRP (>10 mg/l) (table 1$)$. In these patients there was a significant positive correlation between ESR and the rate of superoxide anion radical production in the resting state $(r=0.575, p=0.02)$ or under the stimulation of fMLP $(\mathrm{r}=0.565, \mathrm{p}=0.044)$. However, no significant correlation between CRP concentrations and the rate of superoxide anion radical production was discovered.

Compared with a healthy subject, a patient with AS had a higher intensity of lucigenin enhanced chemiluminescence, with or without the stimulation of fMLP or PMA, than the controls (fig 1). The rate of superoxide anion radical production in patients with AS was significantly higher than that in healthy subjects both when their blood was in the resting condition or was stimulated by either fMLP or PMA, with average increases of 8.8, 4.1, and 4.5 times, respectively ( $\mathrm{p}<0.01$; table 2 ). These patients also showed a significant increase of CMLI in response to stimulation with either fMLP or PMA $(\mathrm{p}<0.01$; table 2$)$.

\section{Discussion}

Although the pathogenesis of ankylosing spondylitis is still unknown, the activation and production of superoxide anion radicals from phagocytes may play a part in the process. Different results have been reported in studies on superoxide anion radical production from PMNs in patients with AS. No difference, or a small difference in superoxide anion radical production of PMNs between patients with AS and healthy subjects, was shown in response to stimulation with FMLP, PMA, or opsonised zymosan. ${ }^{9-11}$ However, the results of this study show that the superoxide anion radical production is significantly higher in patients with AS than in healthy subjects, in the resting state or after stimulation with fMLP or PMA. These results are in agreement with the findings of Wendling ${ }^{12}$ and Biasi, ${ }^{13}$ which show an increase in the oxidative metabolism of the phagocyte system in AS after fMLP stimulation. These different results might be attributable to the methodology or technology used. In recent years, purified phagocytes have been used to study phagocyte function. However, during the purification of phagocytes, activated and primed phagocytes might be lost, and circulating inflammatory mediators might also be removed from serum. Therefore, their free radical measurements might not reflect the exact state of circulating phagocytes; whereas, direct use of whole blood to measure the phagocyte function would minimise artefacts caused by cell purification, and maintain phagocytes in an in vivo physiological state. Furthermore, our method is more sensitive and convenient than the traditional cytochrome $c$ assay and can continuously assess the respiratory bursts from activated phagocytes.

The exact role of superoxide anion radicals in the inflammatory damage of AS has not yet been fully elucidated. NADPH oxidase is a key enzyme that can generate superoxide anion radicals in phagocytes. When phagocytes are exposed to fMLP or PMA the components of $\mathrm{NADPH}$ oxidase form a functional complex responsible for the production of superoxide anion radicals. ${ }^{14}$ In this paper we show that phagocytes of patients with AS are partly activated in the resting condition, and are sensitive to the stimulation of fMLP or PMA. It is highly likely that the sera of patients with AS might have some factors that increase the sensitivity of PMNs in response to fMLP or PMA. These factors could change in number or binding affinity for surface receptors or activate proteins that were in the upstream signal of NADPH oxidase, thus enhancing the superoxide production by NADPH oxidase.

Increased concentrations of interleukin 6 (IL6) and tumour necrosis factor $\alpha(\mathrm{TNF} \alpha)$ in patients with AS were described by Gratacos ${ }^{15}$ and Tutuncu. ${ }^{16}$ In addition, abundant TNF $\alpha$ mRNA was also found in the synovium from inflamed sacroiliac joints. ${ }^{17}$ IL6 can induce systemic inflammation and is said to be the major cytokine responsible for the production of acute phase reactants in the patients with AS. ${ }^{16}$ $\mathrm{TNF} \alpha$ is an inflammatory and priming agent for increased production of reactive oxygen species and matrix metalloproteinases from phagocytes. ${ }^{17}$ When phagocytes are primed by TNF $\alpha$, they become much more sensitive to fMLP or PMA stimulation. In this study we suppose that the phagocytes from patients with AS were primed by $\mathrm{TNF} \alpha$ to enhance their responsiveness to fMLP or PMA stimulation and then trigger respiratory bursts. Therefore, the existence of cytokines (such as IL6 and $\mathrm{TNF} \alpha$ ) in the blood of patients with AS might be the main cause of the inconsistency between various studies.

In conclusion, the production of superoxide anion radicals in the blood of patients with AS is increased either in the resting or stimulated state. The primed phagocytes in the bloodstream are more easily activated by stimulants such as bacterial peptides. The primed or activated phagocytes migrate from bloodstream to specific inflamed joints where abundant $\mathrm{TNF} \alpha$ are found, and they produce large amounts of free radicals and metalloproteinases, leading to joint damage over time. The primed phagocytes may be one of the causative factors in the pathogenesis of ankylosing spondylitis, but further research is required.

We thank Mr Wayne Tsai and Miss Beatrice Wu for their contribution to this paper. Our study was supported by Department of Health ROC under grant DOH87-TD-1053.

1 Brewerton DA, Caffrey M, Hart FD, James DCO, Nicholls Brewerton DA, Caffrey $\mathrm{M}$, Hart $\mathrm{FD}$, James DCO, Nicholls
A, Sturrock RD. Ankylosing spodylitis and HL-A27. Aancet 1973;i:904-7.

2 Mäki-Ikola O, Hällgren R, Kanerud L, Feltelius N, Knutsson L, Granfors K. Enhanced jejunal production of antibodies to klebsiella and other enterobacteria in patients with ankylosing spondylitis and rheumatoid arthritis. Ann Rheum Dis 1997;56:421-5.

3 Yu DTY, Choo SY, Schaack E. Molecular mimicry in HLAB27-related arthritis. Ann Intern Med 1989;111:581-91.

4 Tiwana H, Walmsley RS, Wilson C, Yiannakou JY, Ciclitira PJ, Wakefield AJ, et al. Characterization of the humoral immune response to klebsiella species in inflammatory bowel disease and ankylosing spondylitis. Br J Rheumatol 1998;37:525-31.

5 Nurcombe HL, Bucknall RC, Edwards SW. Neutrophils isolated from the synovial fluid of patients with rheumatoid arthritis: priming and activation in vivo. Ann Rheum Dis 1991;50:147-53.

6 Lu FJ, Lin JT, Wang HP, Huang WC. A simple, sensitive, non-stimulated photon counting system for detection of superoxide anion in whole blood. Experientia 1996;52: $141-4$. 
7 Bennett PH, Burch TA. Population studies of the rheumatic diseases. Bull Rheum Dis 1967;17:453-8.

8 Mancini G, Carbonara HO, Heremans JF Immunochemical quantitation of antigens by single radial immunodiffusion. Immunochemistry 1965;2:361-8.

9 El Abbouyi A, Paul JL, Roch-Arveiller M, Moachon L, Dougados M, Giroud JP, et al. Blood polymorphonuclea behavior in patients with ankylosing spondylitis. Clin Exp Rheumatol 1988;6:401-3.

10 Miller C, Russell AS. The generation of superoxide anions by polymorphonuclear leucocytes from patients with ankylosing spondylitis in response to the stimulant f-met-leuphe. Clin Exp Rheumatol 1986;4:135-7.

11 Ristola M, Leirisalo-Repo M, Repo H. Determination of oxygen radical production in spondyloarthropathies by whole blood chemiluminescence. Ann Rheum Dis 1991; 50:782-6.

12 Wendling D, Didier JM, Vuitton DA. The phagocyte oxidative metabolism function in ankylosing spondylitis. Clin tive metabolism function
13 Biasi D, Carletto A, Caramaschi P, Bellavite P, Andrioli G, Caraffi $\mathrm{M}$, et al. Neutrophil functions, spondylarthropathies and HLA-B27: a study of 43 patients. Clin Exp Rheumatol 1995;13:623-7.

14 Okuyama M, Sakon M, Kambayashi J, Kawasaki T, Monden $\mathrm{M}$. Involvement of protein phosphatase $2 \mathrm{~A}$ in PKC-dependent pathway of neutrophil superoxide generation by fMLP. J Cell Biochem 1996;60:279-88.

15 Gratacos J, Collado A, Filella X, Sanmarti R, Canete J, Llena J, et al. Serum cytokines (IL-6, IL-1 $\beta$ and IFN- $\gamma$ ) in ankylosing spondylitis: a close correlation between serum IL-6 and disease activity and severity. $\mathrm{Br} \mathrm{J}$ Rheumatol 1994;33:927-31.

16 Tutuncu ZN, Bilgie A, Kennedy LG, Calin A. Interleukin-6, acute phase reactants and clinical status in ankylosing spondylitis. Ann Rheum Dis 1994;53:425-6.

17 Cunnane G, Bresnihan B, FitzGerald O. Immunohistologic analysis of peripheral joint disease in ankylosing spondylitis. Arthritis Rheum 1998;41:180-2. 